vaccines and sera for the troops has been very greatly increased; staff are being trained for the administration of military hospitals and for their laboratories, and two mobile laboratories and nineteen military hospital laboratories have been established in the Union. Special military medical problems are being investigated. Other war activities of the Institute include vitamin assays, food analyses for military needs, the production of anti-gas-gangrene serum, the study of insect vectors of disease, plague, relapsing fever, typhus and yellow fever. The list of other researches being done is impressive, and the Institute's routine diagnostic work is evidently one of its most important activities.

\section{Rapid Disappearance of Smallpox}

According to the May issue of the Statistical Bulletin, the organ of the Metropolitan Life Insurance Company of New York, in 1942 for the first time in the history of the United States the number of smallpox cases fell below 1,000. Eleven States were entirely free from the disease, and three other States reported only one case each. Texas alone had more than 100 cases. During the whole year there were less than ten smallpox deaths. In Canada there were only six cases and no deaths. The 897 cases of smallpox reported in the United States in 1942 showed a marked decline from the previous low record of 1,446 cases in 1941 and were only a fraction of the number for 1940,1939 and 1938, when the cases numbered $2,797,9,877$ and 14,977 respectively. In an outbreak of 65 cases in Pennsylvania, the patients had either not been vaccinated or had long outlived their immunity. Apart from 13 unvaccinated school-children, the victims were past middle age.

\section{Production of Rubber in Europe}

A SHORT notice of an article in Agricultura (128, Dec. 1942) entitled "La producción de caucho en Europa" appears in the Revista De Frormacion $Y$ Documentacion Profesional (No. $7 ; 1943$ ). It is pointed out that in the Mediterranean basin it is possible to cultivate plants from which a secretion having the characteristics of rubber has been extracted. This question attained great importance after the occupation of the Ukraine by the enemy, because large tracts there were devoted to the cultivation of koksagyz, a dandelion-like plant, from which it is claimed that fairly satisfactory rubber could be obtained; the percentage of rubber from the extract was as high as 27 . The article suggests that, if to this are added the species which can be cultivated in the Mediterranean basin, and also the synthetic rubber manufactured by the Germans at the Buna works, a possible solution of the natural rubber supply for European countries would be forthcoming.

\section{Maintenance Work in Electrical Supply}

A PAPER on "Maintenance of Distribution Plant and Mains on A.C. Networks" was read before the Institution of Electrical Engineers in London on November 10 by Messrs. F. N. Beaumont and F. A. Geary. They stated that the frequency with which apparatus should be examined, and the time to be allocated for each overhaul, are dependent on $(a)$ the design of the individual unit in relation to its electrical duties and the atmospheric conditions under which it has to operate; $(b)$ the electrical and mechanical strength of the materials employed; (c) the accessibility of the parts requiring normal inspection and testing ; and $(d)$ the physical lay-out and housing of the units, together with the facilities available for carrying out routine maintenance on site. The closest co-operation between the designer and the maintenance engineer is at all times desirable, in order that those details in design which require excessive maintenance may be suitably modified. It is the function of a maintenance engineer to organize the necessary maintenance, examination and testing of all sections of plant under his control, so that the plant may carry out its functional operation successfully and incipient faults be found and eradicated before they lead to failure on the line. The aspects and items of equipment dealt with in the paper are as follows. Staffing, safety precautions, record systems of plant maintenance, switchgear maintenance, batteries, transformers, transformer chambers, fire-fighting installations, protective gear and mains. The paper shows that maintenance, combined with adequate records, can foster improved design, to the mutual advantage of manufacturer and user, in order to obtain for future purposes the best design and lay-out practicable.

\section{Electricity in Mines}

A REVIEw of this subject given (J. Inst. Elect. Eng., 90, Pt. 1, No. 34 ; October 1943) by Mr. J. A. B. Horsley covers the use of electricity in mines under the Coal Mines Acts which are operative in Great Britain. The review gives certain statistical data and surveys technical developments, British Standard specifications, effect of recent legislation, and future developments.

\section{Literature of Penicillin and Similar Substances}

LAST September the National Research Council of Canada issued "Abstracts on Penicillin and other Antibiotic Substances" (National Research Council, Ottawa: No. 1160. 1.00 dollar). Compiled by Miss Muriel E. Whalley, of the Research Plans and Publications Section, it arranges by authors 185 abstracts taken from the American Chemical Abstracts (1917 to Sept. 10, 1943, inclusive) and other material found in the library of the National Research Council of Canada. An index increases the usefulness of this publication and Miss Whalley is to be congratulated on her work. The abstracts deal with the chemical and biological properties of sixteen substances in all. Eight of these are obtained from bacteria, eight from fungi. Among the latter are penicillin, penatin and fumigacin, some of the properties of which have been noted in these columns recently. The properties of patulin were made known too late to be included in Miss Whalley's very useful compilation. As we go to press we learn from the British Medical Journal (Dec. 18, 1943, p. 800) that the January number of the British Medical Bulletin will be devoted to authoritative articles on, and a bibliography of, penicillin.

\section{Rediscovery of Comet Daniel (1909 IV)}

This comet was seen by Mr. G. F. Kellaway, West Coker, on Nov. 30d. 22h., and a few nights later his photographic results confirmed the position which he had adopted for it. Its magnitude at the time of discovery was 13 , and it was very close to the place predicted by Mr. W. P. Henderson and Dr. H. Whichello, in the "Handbook of the British Astronomical Association", 1943. 